\title{
Seasonal, inter-annual and long term variation in top-down versus bottom-up regulation of primary production
}

\author{
Onur Kerimoglu, Dietmar Straile and Frank Peeters \\ O. Kerimoglu (kerimoglu.o@googlemail.com), D. Straile and F. Peeters, Limnological Inst., Univ. of Konstanz, Mainaustrasse 252, \\ DE-78464 Konstanz, Germany.
}

\begin{abstract}
Environmental change strongly affects primary productivity of ecosystems via modifying bottom-up and top-down regulation of primary producers. Here we present a novel approach to quantify the relative importance of regulating factors in natural systems over various time scales: we calculated daily effect sizes of major factors affecting phytoplankton growth during the spring bloom period during almost three decades of lake oligotrophication using numerical experiments with a data based simulation model. We show that with oligotrophication the regulation of spring phytoplankton shifts from primarily top-down to bottom-up, and that the changes in regulation are non-linearly related to the nutrient (phosphorus) concentrations. Our findings indicate that long-term changes in top-down regulation cannot be understood without considering multiple herbivore taxa, here, microzooplankton (ciliates) and mesozooplankton (daphnids). We further demonstrate that bottom-up and top-down regulation are not independent from each other and that their interaction is time-scale dependent.
\end{abstract}

Primary productivity is a key process affecting global carbon fluxes and food web structures in ecosystems. On a global scale, humans alter producer biomass via changing e.g. global input rates of major plant nutrients (Jeppesen et al. 2005, Smith and Schindler 2009), herbivore abundances (Hughes 1994, Miehe et al. 2010) and climatic conditions (Behrenfeld et al. 2006, Boyce et al. 2010). In the face of future environmental change, a better understanding of the control of primary productivity and producer biomass is hence an immediate issue of ecological research (Elser et al. 2007, Gruner et al. 2008).

Ever since the seminal work of Hairston et al. (1960), determining whether the abundance of organisms at a given trophic level is regulated by bottom-up factors such as resource availability or top-down factors such as predation has been a major goal in ecological research (Oksanen et al. 1981, McQueen et al. 1989, Elser and Goldman 1991). Ecologists nowadays recognize the simultaneous operation of top-down and bottom-up processes, and focus on their relative importance (Osenberg and Mittelbach 1996), interaction (Leibold 1989) and the response of relative importance and interactions to environmental change (Osenberg and Mittelbach 1996, Gruner et al. 2008, Menge 2000). Addressing these issues requires quantification and comparison of the 'effect sizes' of bottom-up versus topdown factors (Osenberg and Mittelbach 1996) and consideration of temporal scales encompassing multiple generations of interacting populations and emerging feedback effects therein (Gruner et al. 2008).
It is well known that the identity and intensity of interactions experienced by communities substantially vary throughout the season, or along successional stages (as in Sommer et al. 1986). Particularly in plankton ecology, population densities can change by orders of magnitude within a couple of weeks (Elser and Goldman 1991). Seasonal changes in the intrinsic dynamics and in the environmental conditions can cause intra-annual variability in the relative importance of top-down versus bottom-up processes. For example, Hoekman (2010) reported increasing top-down effects with seasonally increasing temperatures. Inter-annual variability or long-term changes in abiotic conditions can also have substantial effects on species interactions and cause inter-annual changes in the relative importance of bottom-up and top-down control of species. Climate warming, for instance, through its differential effects on the phenology of interacting species, were shown to disrupt predator-prey interactions (Winder and Schindler 2004), which can consequently diminish top-down control. Likewise, changes in rainfall patterns were found to alter the relative importance of top-down versus bottom-up forcing communities in terrestrial ecosystems (Meserve et al. 2003). All these complexities point to a need for an assessment of interactions with consideration of both inter- and intra-annual time scales.

It is also increasingly recognized that there is a need to consider the composition and diversity within a trophic level, as different species within a guild can complement each other with regard to the total exerted impact on another 
guild, and as different species can exhibit different responses to changing conditions (Leibold et al. 1997, Persson 1999, Bakker et al. 2006). In lake ecosystems, mesozooplankton (especially waterfleas of the genus Daphnia) and microzooplankton (especially ciliates) are considered to be the most important herbivores (Weisse et al. 1990, Tirok and Gaedke 2006). Due to their differences in size and life histories (Weisse 2006) both taxa are expected to differ in their response to algal dynamics, suggesting the necessity to study the top-down effects of at least these two taxa on phytoplankton separately.

Here we use a novel combination of long-term observations and dynamic simulations to study the regulation of spring phytoplankton dynamics. Bottom-up limitation of phytoplankton by phosphorus is compared to top-down limitation due to grazing by micro- and mesozooplankton at a daily resolution during almost three decades of nutrient reduction in a well studied planktonic system. In this study, we focus on the spring bloom period, as the food webs in aquatic systems later in the season generally become more complex and the community structures change towards increasing functional heterogeneity (Sommer et al. 1986). Our analysis reveals differential variation in the impacts of the studied factors on spring phytoplankton at seasonal and long-term time scales and demonstrates a shift from the predominance of top-down to bottom-up forcing along a transition from eu/mesotrophic towards oligotrophic conditions. Our approach based on short and long-term quantification of the effect sizes of different potentially limiting factors provides novel insights into the seasonal and long-term dynamics of phytoplankton regulation.

\section{Material and methods}

\section{General approach}

The relative importance of bottom-up versus top-down regulation was quantified by combining the information from a long-term data set with a biological model driven by temperature and diffusivity profiles estimated by a hydrodynamical model. The detailed long-term data set with a high temporal resolution was utilized to limit the number of state variables and hence the complexity of the biological model as the concentrations of soluble reactive phosphorous (SRP) and zooplankton (Daphnia, Bosmina sp., cyclopoid copepods, Eudiaptomus gracilis) biomass were not simulated dynamically but taken from the measurements. As measurements of ciliate biomass were only available for some of the years (1987-1998 and 2006-2007) we estimated ciliate biomass for all years from a dynamic simulation of a coupled ciliate-phytoplankton model that was validated with the available data on ciliates and phytoplankton. These estimates of ciliate biomass were then treated in the same way the data for other zooplankton groups were treated to force the un-coupled phytoplankton model. The importance of each regulating factor was quantified by comparing a model run that included all limiting factors with model runs in which limitation by one of the factors in focus, i.e. nutrients, ciliates or daphnids was removed (for details see below).

\section{Model description}

The employed model is based on the vertically resolved phytoplankton model of Peeters et al. (2007b) which was extended to include nutrient limitation of algal growth. The dynamics of phytoplankton carbon concentration $A$, in the vertically resolved water column ( $z$ indicating the depth) is described by the partial differential equation:

$\frac{\partial A}{\partial t}=\gamma_{A} P_{A} A-D_{A} A+S-\sum_{i} I_{i} Z_{i}+\frac{\partial}{\partial z}\left(K_{z} \frac{\partial A}{\partial z}\right)-v_{A} \frac{\partial A}{\partial z}$

where $\gamma_{A}$ is the phytoplankton production efficiency (1 respiration proportional to growth), $P_{A}$ is the specific growth rate of phytoplankton, $D_{A}$ is the specific mortality rate of phytoplankton, $Z_{i}$ and $I_{i}$ are respectively the carbon biomass concentration and ingestion rate of zooplankton group $i, S$ is seeding, $K_{z}$ is the vertical turbulent diffusivity and $v_{A}$ is the sinking rate. Nutrient limitation was parameterized as a Monod function of nutrient availability $(N)$. We consider a single limiting nutrient, phosphorus, which is read from data files as soluble reactive phosphorus concentrations at $0,1,2.5,5,7.5,10,15$, $20,30,50,100,150,200,230$ and $250 \mathrm{~m}$ depth and linearly interpolated to the model grid. Nutrient limitation is coupled to light limitation by assuming that the combined effect is the minimum of two factors according to the Liebig's law of the minimum (Von Liebig 1840):

$P_{A}(z)=\theta^{-1} p_{s p}^{\max } \times \min \left[\tanh \left(\frac{\alpha L(z)}{p_{s p}^{\max }}\right), \frac{N(z)}{N(z)+K_{N}}\right]$

where $\theta$ is the carbon:chlorophyll- $a$ (hereafter chl a) ratio, $p_{s p}^{\max }$ is the chlorophyll specific production rate, $\alpha$ is the initial slope of the light dependent growth curve, $L$ is light intensity and $K_{N}$ is the half saturation constant for nutrient limited growth. Light intensity is calculated at each time step according to the Lambert-Beer law while light extinction attenuation is calculated according to Tilzer (1988):

$L(z)=L_{0} \times e^{\int^{i}\left(\eta_{b}+\eta_{c b l} A\left(z^{\prime}\right) \theta^{\prime}\right) d z^{\prime}}$

where $\eta_{b}$ and $\eta_{c b l}$ are respectively the background and chlorophyll-specific light extinction coefficients, $L_{0}$ is the incident light intensity available in hourly resolution and $z^{\prime}$ is the integration variable. Seeding, $S$ refers to a small and constant amount of phytoplankton input, i.e. $0.01 \mathrm{mg} \operatorname{chl} a \mathrm{~m}^{-3} \mathrm{~d}^{-1}$ throughout the water column. It basically improves the representation of algae over the winter and can be associated with various mechanisms such as horizontal transport of algae produced in the littoral zone.

As in the case of the limiting nutrient, herbivore abundances were not dynamically simulated but taken from data, which are available as total carbon biomass in the upper 0-20 meters for ciliates and in the entire water column for Daphnia, cyclopoid copepods, Eudiaptomus and Bosmina. A type-2 functional response is assumed for all the herbivores, as parameterized by a Monod function: 


$$
I_{i}=I_{\text {max }, i} \frac{A(z)}{K_{i}+A(z)}
$$

where $I_{\max , i}$ and $K_{i}$ are the maximum ingestion rate and half saturation constant of the species $i$. For Daphnia, cyclopoid copepods, Eudiaptomus and Bosmina, the measured biomasses $\left(Z_{i}\right.$, data $)$ were assumed to be originating from the top $20 \mathrm{~m}\left(Z_{i}(z)=0\right.$ for $\left.z>20\right)$. Further, it was assumed that their vertical distribution within the top $20 \mathrm{~m}$ follows that of their food (chl- $a$ ) according to:

$$
Z_{i}(z)=\frac{A(z)}{\int_{0}^{20} A(z) d z} Z_{i, \text { data }}
$$

Ciliate data in fact exists only for a limited time period (1987-1998, 2006-2007). In order to obtain a data set covering the entire time period of 28 years considered in this study, an extended version of the phytoplankton model including a dynamic grazer compartment parameterized for ciliates was employed. Coupled to the phytoplankton compartment in Eq. 1, the dynamics of ciliates, $Z_{c i l}$ was described by the partial differential equation:

$\frac{\partial Z_{c i l}}{\partial t}=\gamma_{c i l} I_{c i l} Z_{c i l}-D_{c i l} Z_{c i l}$

where $\gamma_{c i l}$ is the gross growth efficiency and $D_{c i l}$ is the density dependent mortality rate of ciliates due to predation. The specific mortality rate increases linearly with ciliate biomass with slope $d_{c i l}$ :

$D_{c i l}=d_{c i l} Z_{c i l}$

resulting in a quadratic mortality term (Steele and Henderson 1981, Edwards and Yool 2000).

Finally, all the kinetic model parameters (Table 1) were modified for the ambient temperature by the $Q_{10}$ law (not shown in the above equations to facilitate readability)

$r(T)=r(10) \times Q_{10}^{(T / 10-1)}$

Where, $r(T)$ is the rate at ambient temperature $(T)$ and $r(10)$ is the rate at $10^{\circ} \mathrm{C}$.

\section{Model operation}

Model operation and implementation was as in Peeters et al. (2007b). Vertical profiles of temperature and turbulent diffusivities are calculated by the $1-\mathrm{D}$ physical lake model SIMSTRAT (Goudsmit et al. 2002, Peeters et al. 2002) with ten minute time steps. Light extinction coefficients were calculated from the measured chl $a$ data according to Eq. 3. Meteorological data was provided with hourly resolution. SIMSTRAT was calibrated with biweekly to monthly temperature profiles from 1979 to 1984 and qualitatively validated for the period 1987-1994 (details in Peeters et al. 2007b). The model was initialized in 1979

\begin{tabular}{|c|c|c|c|c|}
\hline Symbol & Description & Unit & Value & Source \\
\hline \multicolumn{5}{|c|}{ Kinetic parameters (reference temperature $=10^{\circ} \mathrm{C}$ ) } \\
\hline$p_{s p}^{\max }$ & algae max. specific growth rate & $\operatorname{mg~C~} \mathrm{mg} \mathrm{chl} \mathrm{a}^{-1} \mathrm{~d}^{-1}$ & 67.2 & 1 \\
\hline$D_{A}$ & algae mortality & $d^{-1}$ & 0.02 & 2 \\
\hline$d_{\text {cil }}$ & ciliate quadratic mortality constant & $m^{3} \mathrm{mg} \mathrm{C}^{-1} \mathrm{~d}^{-1}$ & 0.0025 & 12 \\
\hline$I_{\text {cil }}$ & ciliates max. ingestion rate & $d^{-1}$ & 2.8 & 3 \\
\hline$I_{\text {daph }}$ & Daphnia max. ingestion rate & $d^{-1}$ & 0.8 & 4 \\
\hline$I_{\text {bos }}$ & Bosmina max. ingestion rate & $d^{-1}$ & 0.5 & 4 \\
\hline$l_{\text {cop }}$ & Copepod max. ingestion rate & $d^{-1}$ & 0.5 & 5 \\
\hline$Q_{10}{ }^{a}$ & temp. dependence of autotr. processes & - & 2.3 & 1 \\
\hline$Q_{10^{Z}}$ & temp. dependence of heter. processes & - & 2 & 6 \\
\hline \multicolumn{5}{|c|}{ Other biological parameters } \\
\hline$\theta$ & $\mathrm{C}: \mathrm{Chl}$ & $\mathrm{C} \mathrm{Chl}^{-1}$ & 20 & 7 \\
\hline$K_{N}$ & Nutrient (phosphorus) half sat. constant & $\mathrm{mg} P \mathrm{~m}^{-3}$ & 8 & 12 \\
\hline$K_{\text {cil }}$ & half sat. const. for grazing by ciliates & $\operatorname{mg~Cl-1}$ & 0.75 & 3 \\
\hline$K_{\text {daph }}$ & half sat. const. for grazing by Daphnia & $\operatorname{mgCl} \mathrm{Cl}^{-1}$ & 0.5 & 4 \\
\hline$K_{\text {bos }}$ & half sat. const. for grazing by Bosmina & $\operatorname{mgC} \mathrm{Cl}^{-1}$ & 0.13 & 4 \\
\hline$K_{\text {cop }}$ & half sat. const. for grazing by copepods & $\operatorname{mg~Cl-1}$ & 0.5 & 5 \\
\hline$\gamma_{A}$ & algal production efficiency (1-resp.) & - & 0.8 & 2 \\
\hline$\gamma_{C}$ & ciliates gross growth efficiency & $\mathrm{C}_{\mathrm{cil}} \mathrm{C}_{\mathrm{alg}}{ }^{-1}$ & 0.3 & 8 \\
\hline$S$ & Phytoplankton seeding rate & $\mathrm{mg}$ chl a m $\mathrm{m}^{-3} \mathrm{~d}^{-1}$ & 0.01 & 12 \\
\hline \multicolumn{5}{|c|}{ Physical parameters } \\
\hline$V_{A}$ & algae sinking rate & $m d^{-1}$ & 0.2 & 9 \\
\hline$\eta_{b}$ & background light absorption coeff. & $\mathrm{m}^{-1}$ & 0.27 & 10 \\
\hline$\eta_{c h l}$ & chl. specific light absorption coeff. & $\mathrm{m}^{2} \mathrm{mg} \mathrm{chla}$ & 0.021 & 10 \\
\hline$\alpha$ & slope of the light $(\mathrm{L})$ - growth $(\mathrm{P})$ curve & $\mathrm{gCg}$ chl $\mathrm{a}^{-1} \mathrm{~m}^{2} \mathrm{~W}^{-1} \mathrm{~d}^{-1}$ & 0.82 & 11 \\
\hline
\end{tabular}

Table 1. Model parameters.

Sources: 1) Haese et al. (1998), 2) Geider and Osborne (1989), 3) consideration of values presented in Weisse et al. (2001) and those used by Buitenhuis et al. (2010) and Bruce et al. (2006), 4) mean values of the corresponding groups in Hansen et al. (1997), 5) Santer and Van den Bosch (1994), 6) as a rule of thumb, 7) Peeters et al. (2007b), 8) Straile (1997), 9) Sommer (1984), 10) Tilzer (1988), 11) Haese (1996) citing Bannister (1974), 12) manually adjusted. 
and run continuously until 2007 to generate vertical diffusivity and temperature profiles with $1 \mathrm{~m}$ spatial resolution and hourly temporal resolution.

The vertical temperature and diffusivity profiles and incident light intensity at the time steps required by the biological model were calculated by linear interpolation. The biological model was operated at a vertical resolution of $1 \mathrm{~m}$ and was initiated at the first day of each year with the interpolated chl $a$ concentration measurements. For the initial ciliate profiles to be used at the first day of each year, firstly the top $20 \mathrm{~m}$ integrated biomasses were estimated for the years ciliate data were absent by linearly regressing the ciliate abundances on chl $a$ concentrations. Then, vertical distribution in the top $20 \mathrm{~m}$ was assumed to be proportional to chl- $a$ profiles, as in the case of other zooplankton. However, since it was believed that the ciliates would not be able to resist against mixing and therefore cannot constrain themselves in the top $20 \mathrm{~m}$, it was further assumed that ciliates exist also below $20 \mathrm{~m}$, with the same proportionality as in the top $20 \mathrm{~m}$ (Peeters et al. 2007b). Therefore, Eq. 5 was used for the whole depth range $(z=0-250)$. However, model results for the top $20 \mathrm{~m}$ are not sensitive to this last assumption. The set of ordinary differential equations for the biological model was solved with the implicit MATLAB algorithm ODE15S with dynamic time stepping.

\section{Study site and data set}

Lake Constance is a deep $\left(z_{\max }: 254 \mathrm{~m}\right)$ warm-monomictic lake characterized by a consistent reduction of phosphorus loading during the last decades (Stich and Brinker 2010). The two most important herbivore groups during the spring period in Lake Constance are recognized to be daphnids and ciliates. The contribution of other taxa (e.g. Bosmina, copepods and rotifers) to herbivory has been shown to be of minor importance during spring (Gaedke et al. 2002, Tirok and Gaedke 2006). Hence, we concentrate on daphnid and ciliates as agents of top-down control in this study.

The meteorological data set used as input for both the physical model and the biological model consisted of hourly measurements of wind speed, wind direction, air temperature, solar radiation, relative humidity and cloud cover obtained from the Konstanz Meteorological station. The monthly to biweekly temperature profiles used for the calibration of SIMSTRAT were obtained from the deepest location in the main basin while the high resolution data used to validate the model were obtained with thermistor chains deployed at the deepest location in the western basin of Lake Constance (details in Peeters et al. 2007b). Plankton samples were collected weekly during the growing season at the deepest location of the western basin since 1979. However, chl a concentrations were not measured in 1984 and 1985, Daphnia abundances not in 1983 and ciliate abundances not during 1979-1986 and 1999-2005. Daphnid and ciliate biomasses were calculated from abundances and size structures according to Weisse and Mueller (1998) and Gaedke et al. (2002). As daphnid biomasses were not available in 1983 this year was excluded from our analysis. Soluble reactive phosphorus (SRP) concentrations were measured at the center of Upper Lake Constance.

\section{Quantification of the impact of a factor controlling phytoplankton growth}

We adopt the definition by (Osenberg and Mittelbach 1996), who quantified limitation as 'an index that isolates the effect of a limiting factor on per capita population growth', i.e. algae growth in our study. Assume that the specific growth rate of algae can be written in the form:

$r(\varphi)=\frac{d A}{A d t}=\frac{d(\ln A)}{d t}$

where $A$ is the concentration of algae and $\varphi$ stands for a specific parameter set describing the control of phytoplankton growth by the relevant factors (e.g. light, nutrients, herbivores, etc.). If the initial concentrations of control and treatment runs are identical, the degree of limitation $\Delta r_{f}$ due to a certain factor $f$, can be approximated by:

$\Delta r_{f}=\frac{\ln \left(A_{t, T} / A_{t, C}\right)}{\Delta t}$

where, over a manipulation duration $\Delta t, A_{t, C}$ is the final algae concentration attained by a control simulation in which limitation by all considered factors were at ambient levels and $A_{t, T}$ is the final algae concentration attained by a treatment simulation in which the limitation by factor $f$ was completely eliminated while holding the other factors at ambient levels. $\Delta r_{f}$ has been used as a measure of effect size in meta-analyses (Downing et al. 1999) as well as to quantify 'interaction strength' in food webs (Berlow et al. 1999). The interpretation of $\Delta r_{f}$ as a measure of limitation due to a certain factor $f$ requires that the manipulation duration is shorter than the time needed for feedback mechanisms to emerge (Downing et al. 1999). In this study, the manipulation duration was chosen to be 1 day $(\Delta t=1)$ to capture the overall outcome of day and night time activity. $\Delta r_{f}$ for each of the three limiting factors considered here, i.e. nutrients (phosphorus), ciliates and Daphnia were calculated at each $1 \mathrm{~m}$ depth interval and for each day during the spring bloom of each year for the period 1980-2007. The daily average $\Delta r_{f}$ in the top $20 \mathrm{~m}$ of the water column will be referred to as the 'impact' of the respective factor. For each day, initial phytoplankton concentrations for both control and treatment runs were taken from a baseline simulation, in which nutrient, ciliate and daphnid concentrations were at ambient levels (as in the control runs). Resource limitation due to phosphorus was removed by setting the phosphorus half saturation of algae growth to 0 , whereas predation pressure of ciliates and Daphnia was removed by setting their filtering rates to 0 .

Interannual meteorological variability has been shown to have a strong influence on spring phenology, i.e. both, the start of the spring bloom via the establishment of stratification (Peeters et al. 2007b) and also the end of the spring bloom via temperature controlled grazing losses, i.e. onset of the clear-water phase (Straile 2000). 
Consequently, impacts calculated for a fixed calendar date or month could be strongly influenced by interannual meteorological variability. As we are interested in analyzing the changes in phytoplankton regulation along an oligotrophication gradient, we aimed to reduce a possibly confounding influence of interannual phenological variability, by considering the impacts within a 'spring bloom' period that is separately identified for each year, rather than referring to fixed calendar dates. The definition for the start and end of the spring bloom period follows criteria already established for Lake Constance: the onset of spring bloom was defined as the day when measured average chl $a$ concentration in the top $20 \mathrm{~m}$ exceed a value of $3 \mu \mathrm{g} \mathrm{I}^{-1}$ (Peeters et al. 2007a). The end of the bloom was defined as the emergence of clear water phase (hereafter CWP), i.e. the first day after the bloom onset when the measured Secchi depth exceeds $7 \mathrm{~m}$ (Straile 2000). Chlorophyll data is not available for the years 1984 and 1985 and in these two cases the mean onset time of the other years, i.e. 30 March, was used as bloom onset. The Secchi depth criterion was not met in 2000 and 2002 and for these two cases the mean CWP time of the other years, i.e. 31 May, was assumed. Throughout the text, we refer to the time period between the onset and the end of the bloom as 'entire spring', to the first 21 days after the onset as 'early spring' and to the last 21 days before the end of the bloom as 'late spring' period. The chosen time window of 21 days allows smoothing out the influence of short lasting fluctuations and avoids significant overlap between the early and late spring period (in 2004, six days are shared as the single case of overlap, while in four other years, the early and late periods span the entire spring period). Note that our conclusions are qualitatively rather insensitive to the length of the time window and remain essentially the same if the time windows are 10, 21 or 31 days.

\section{Statistical methods}

We tested for the existence of monotonic long-term trends of impacts during the three seasonal periods with Kendall's rank correlation coefficient $(\tau)$ using Bonferroni corrected significance levels. The relationship between the average concentrations of SRP during winter mixing $\left(\mathrm{SRP}_{\text {mix }}\right)$ and average entire spring impacts and chl $a$ concentrations, was described by a function of Monod type $(y=c+a \times x /(b+x))$, which allowed to fit both saturating $(a>0)$ and hyperbolically decreasing $(a<0)$ relationships. Akaike's information criterion corrected for small sample sizes (AICc) was used to judge whether these non-linear fits were superior to the respective linear fits. Models with a smaller AICc can be considered superior when the difference to the AICc of other models exceeds 2 (Anderson et al. 1998).

\section{Results}

$\mathrm{SRP}_{\text {mix }}$, which is a good indicator of the lake's trophic state, declined steadily from the start of the study period until recent years, when $S R P_{\text {mix }}$ concentrations leveled off

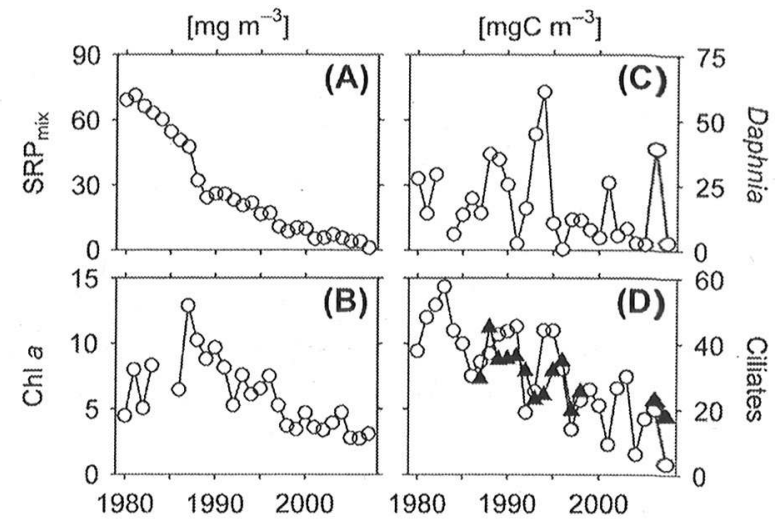

Figure 1. Long-term development of (A) SRP concentrations ( $\mathrm{mg} \mathrm{P} \mathrm{m}^{-3}$ ) during winter mixis, and of mean spring concentrations of (B) chl $\left.a 8 \mathrm{mg} \mathrm{m}^{-3}\right)$, (C) Daphnia $\left(\mathrm{mg} \mathrm{C} \mathrm{m}^{-3}\right)$, and (D) ciliate $\left(\mathrm{mg} \mathrm{C} \mathrm{m}^{-3}\right)$ biomass. All values represent average values of the upper $20 \mathrm{~m}$ of the water column. For ciliates observed (filled triangles) and simulated average biomasses (circles) in the respective study years are shown.

at value of approximately 6-7 $\mu \mathrm{g}^{-1}$ (Fig. 1A). Average chl a concentrations during spring did not respond to declining phosphorus concentrations until the mid 1980s, but decreased thereafter (Fig. 1B). Average Daphnia biomasses during spring showed a high variability throughout the study period, but did not decline significantly (Fig. 1C) whereas the ciliate biomasses decreased with time throughout the study period (Fig. 1D). Both, the interannual (Fig. 1D) and seasonal (Fig. 2A) variability of ciliate biomass measured during the spring bloom period were adequately reproduced by the model. This enabled in turn, to run the phytoplankton model with simulated ciliate concentrations as a static compartment as in the case of Daphnia during the spring bloom period across the entire range of the available data, i.e. from 1980-2007, which covers almost the complete course of oligotrophication. It should be noted that, although some ciliate blooms during the summer months were not captured by the model (Fig. 2A), these discrepancies do not confound our analysis, as these blooms occurred after the onset of clear water phase.

The phytoplankton model realistically reproduced the seasonal courses, as well as the interannual and the long term variation of algal densities for almost three decades exhibiting a wide range of trophic states and climatic variability (Fig. 2B). The good agreement between simulated and measured long term changes in the timing and intensity of blooms suggests that the model adequately accounts for the relevant biological processes.

Daily impacts of ciliates, Daphnia and phosphorus varied strongly throughout the season as is exemplified for two years representing eutrophic and oligotrophic conditions (Fig. 3). In the eutrophic period, e.g. in 1980, phosphorus limitation remained generally low and only increased at the end of spring (Fig. 3C) while in the oligotrophic period, e.g. 2001, phosphorous became limiting already at the beginning of the growth season (Fig. 3D). The seasonal course of the impact of herbivores was parallel to 

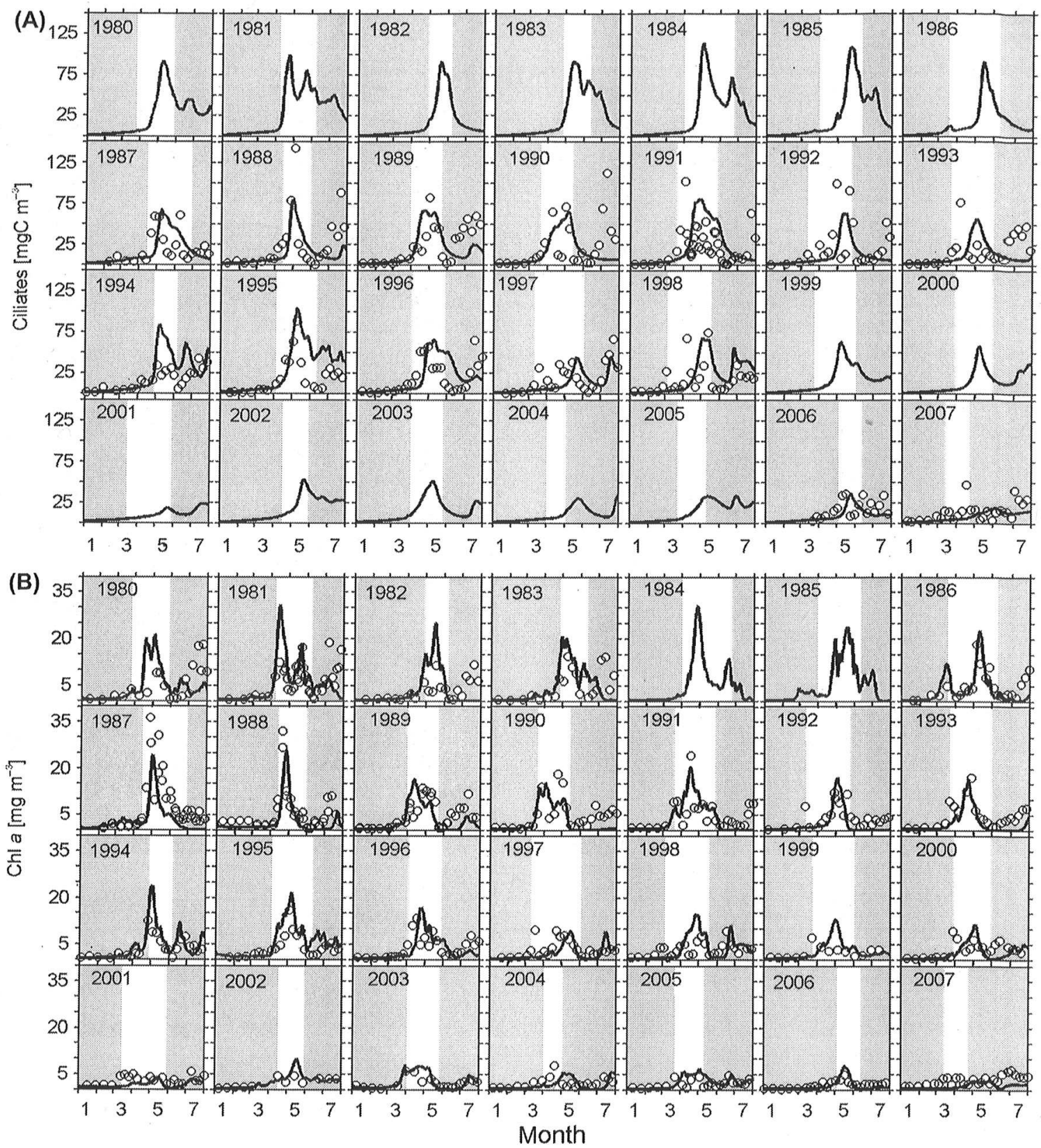

Figure 2. Average observed (points) and modeled (line) concentration of (A) ciliates and (B) chl $a$ in the top $20 \mathrm{~m}$. Intervals before the onset of bloom and after the onset of clear water phase are shaded in gray.

the seasonal course of their abundance (Fig. 3E-H). The temporal variability of the herbivore impacts is much smaller than that of the phosphorus impacts (Fig. 3) because of the effects of light limitation. Whereas herbivore impacts are independent of light limitation, the interactive effects of light and nutrients on specific production cause phosphorous impacts to be a function of the ambient light availability. Daily fluctuations in light intensity are thus reflected in the variability of the phosphorus but not of the herbivore impacts.

Average daily impact of phosphorus within the entire, early and late spring periods increased from 1980 to 2007
( $<<0.01$, Fig. 4A-C). The average daily impact of phosphorus in the late period is considerably higher than in the early period, due to the low phosphate concentrations at the end of the spring period resulting from uptake by phytoplankton. In contrast to the increasing impacts of phosphorus, average daily impact of ciliates (Fig. 4D-F) within the late and entire spring periods significantly decreased over the 28 years. The impact of ciliates in the late period is higher than in the early period (Fig. 4E-F), in most of the years. The impacts of Daphnia during the early spring period were very low, in accordance with the low Daphnia abundances in early spring, whereas 

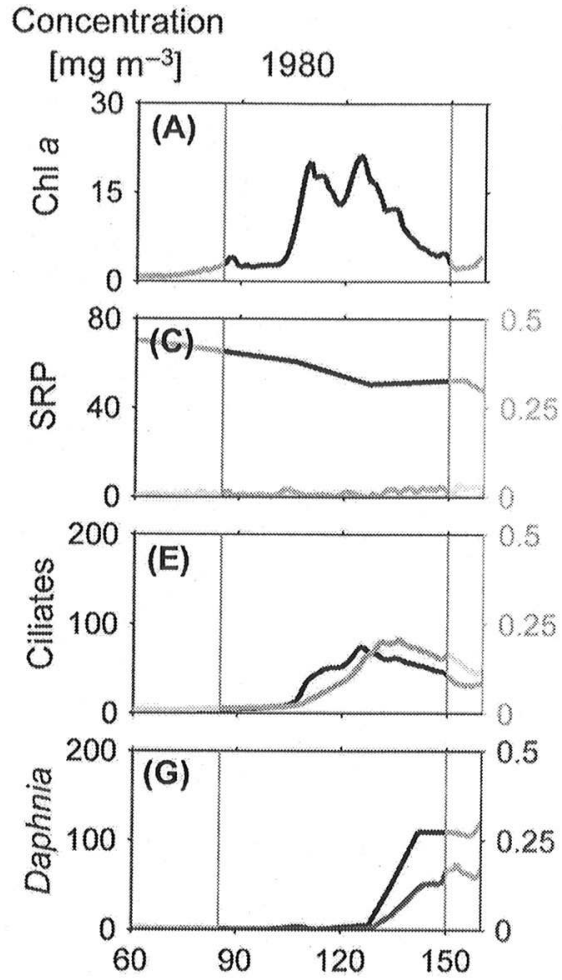

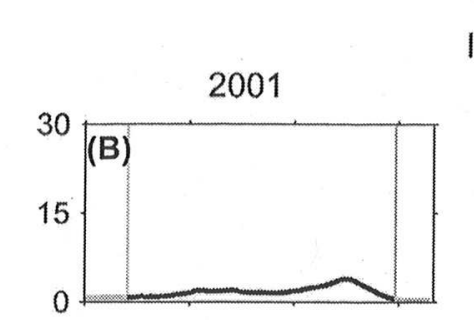

Impact

$\left[d^{-1}\right]$
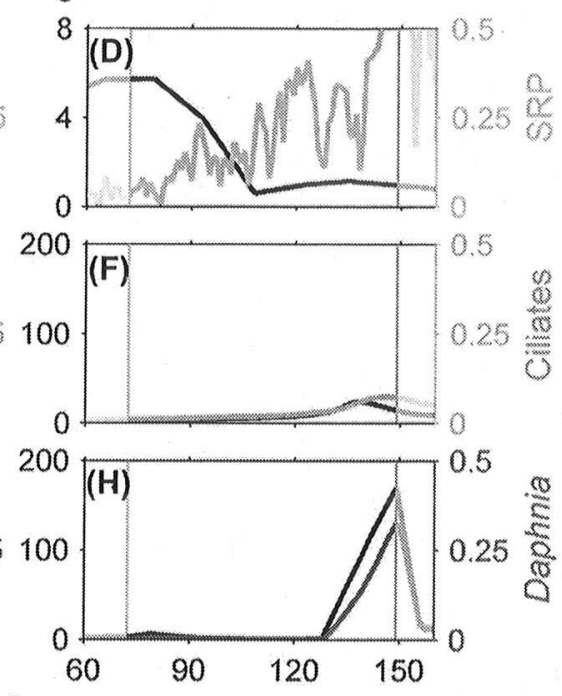

Day of year

Figure 3. Simulated chl $a$ concentrations $(0-20 \mathrm{~m})$ that set the initial concentrations for the experiments (A, B), concentration (black lines, left axes) and daily impact (colored lines, right axes) of phosphorus (C, D), ciliates (E, F) and Daphnia (G, H) for two example years, 1980 and 2001. Intervals before the onset of bloom and after the onset of clear water phase are shaded.

during the late and the entire spring period impacts were higher, but did also not change significantly during the 28 years studied $(\mathrm{p}>0.1$, Fig. 4G-I). Total (phosphorus + ciliates + Daphnia) impacts increased within the 28 years in early $(\mathrm{p}<0.01)$ and entire $(\mathrm{p}<0.1)$ spring periods, but not in the late spring (Fig. $4 \mathrm{~J}-\mathrm{L}$ ).

The relative contribution of different factors to the total impact illustrates that there has been a transition from a top-down dominated limitation of phytoplankton during the eu/mesotrophic 1980s and 1990s to a bottomup dominated limitation in the recent oligotrophic years (Fig. 5). In late spring, the impacts of Daphnia and ciliates were of comparable magnitude (Fig. 5C), whereas, in most of the years, the impact of ciliates exceeded the impact of Daphnia when the entire spring is considered (Fig. 5A). The latter is due to the very low abundance of Daphnia in early spring (Fig. 5B). However, the strong decline in the impacts of ciliates and the rather constant impacts of Daphnia resulted in a gradual decrease in the difference between the relative importance of the two herbivores in limiting phytoplankton growth.

Average total impacts as well as impacts of phosphorus and ciliates during the entire spring period were significantly (all Monod fits: $\mathrm{p}<0.01$ ) related to $\mathrm{SRP}_{\text {mix }}$, but not the impacts of Daphnia (Monod fit and linear fit, $p>0.1$ ) (Fig. 6). The relationships of the former three to SRP were non-linear and could be adequately described with a saturating function of $\mathrm{SRP}_{\text {mix }}$ which is exemplified by a fitted Monod function (Fig. 6B, C, E). Likewise, mean spring chl $a$ concentration was also a saturating function of $\mathrm{SRP}_{\text {mix }}(\mathrm{p}<0.001$, Fig. 6A). In all cases with significant non-linear fits, the difference in AICc between nonlinear and linear models was $\geq 2$, suggesting that non-linear fits can be regarded as superior to linear fits.

\section{Discussion}

In this study, we investigate algal growth limitation by integrating the established concepts of experimental analyses typically used for estimating interaction strength (Berlow et al. 1999), with an elaborate modelling technique that utilises a long term data set with exceptionally high temporal resolution. The technique allows quantifying the limitation of phytoplankton growth by nutrients and grazers at a daily resolution over 28 years by data driven numerical experiments, hence, examining seasonal and inter-annual variability as well as long-term changes in the regulation of primary production along a productivity gradient.

The metrics chosen in our study, i.e. the impacts, are a measure of the daily net specific-production of phytoplankton in the upper $20 \mathrm{~m}$ of the water column that is not realized because of nutrient limitation or grazing by ciliates and daphnids. The results we obtained for these impacts make intuitive sense. For example, the total impacts on phytoplankton increased during the study period, which is 


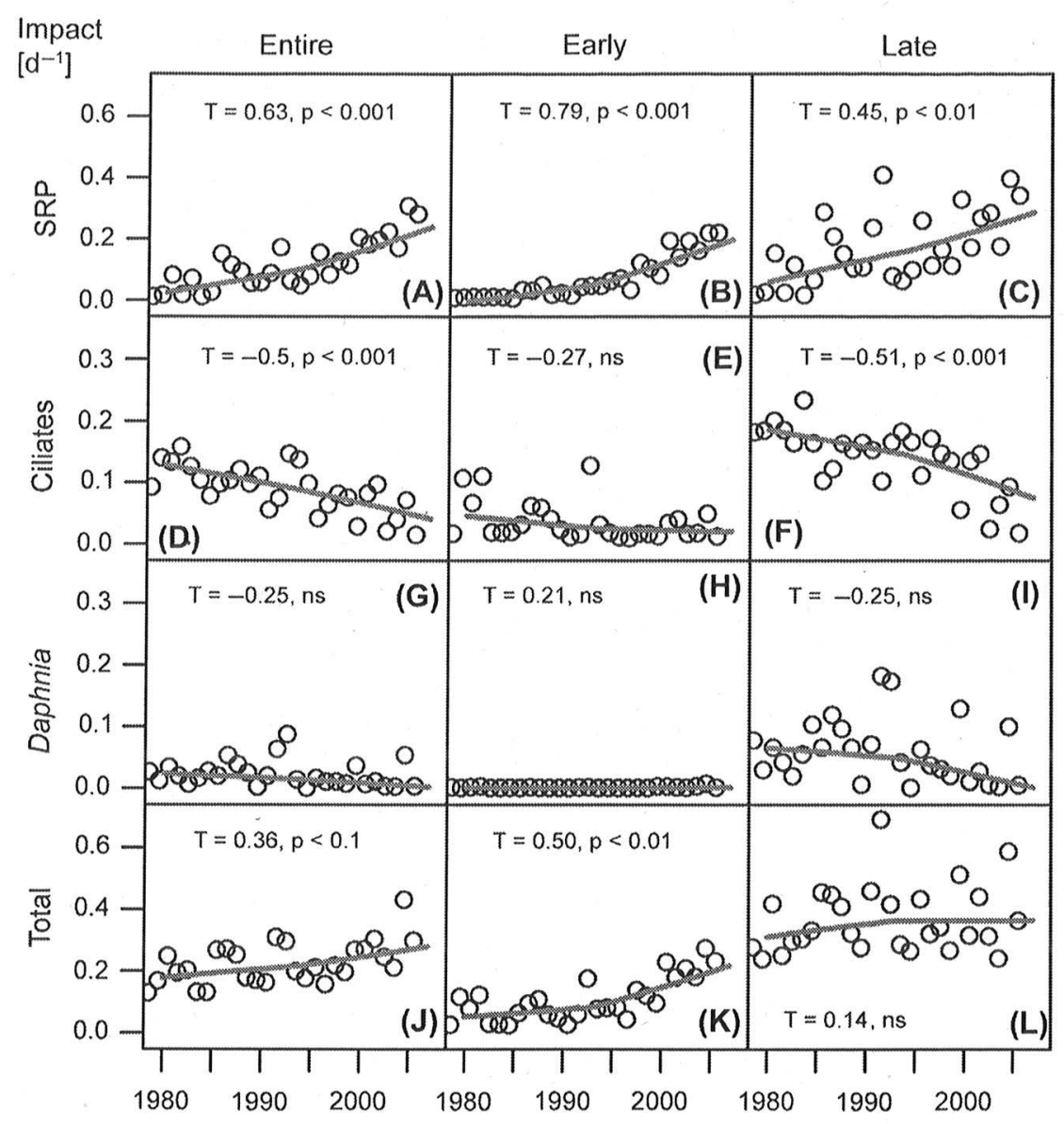

Figure 4. Average top $20 \mathrm{~m}$ impact of phosphorus (A-C), ciliates (D-F), Daphnia (G-I), and their sum (J-L) within the entire spring, defined as the period between the onset of bloom and clear water phase (A, D, G, J); early spring, defined as the first three weeks after bloom onset (B, E, H, K); and late spring, defined as the last three weeks until the clear water phase (C, F, I, L).

consistent with the long-term decline of spring phytoplankton biomass as a result of oligotrophication. Likewise, the increase in the total impact over the last 28 years especially occurred during the early spring period, but not during the late spring period because the total impact during late spring was already high during eu/mesotrophic years. This is consistent with a strong decline of phytoplankton biomass towards the clear-water phase during all study years.
We use measured herbivore and phosphorus concentrations to drive the phytoplankton model instead of developing a full model with herbivores and phosphorus as dynamical variables. This enabled us to match the phytoplankton dynamics most closely and to keep the model uncertainty low, allowing an almost direct transformation of the in situ measurements to interaction strengths. The presented technique is ideal for isolating the direct effect

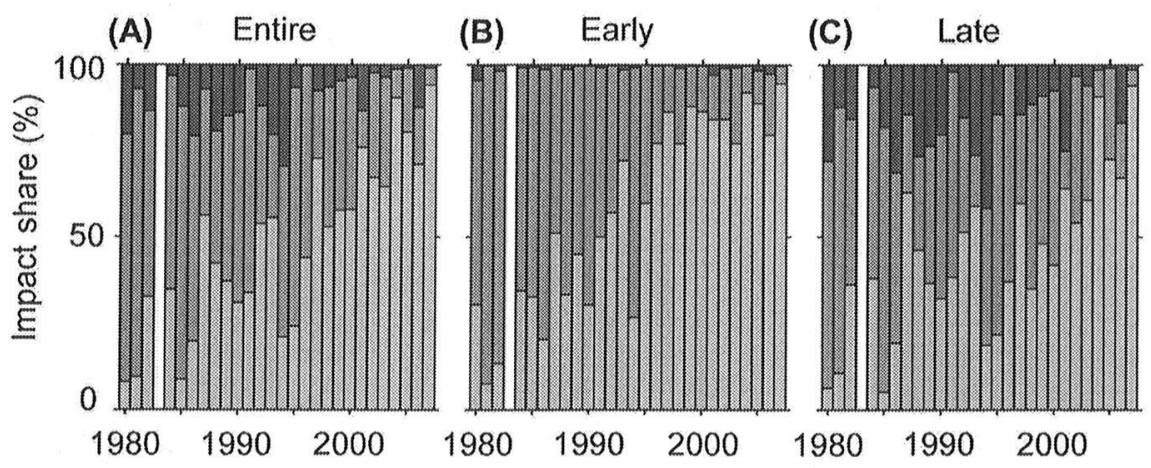

Figure 5. Impact share of phosphate (orange) ciliates (light blue) and Daphnia (dark blue) within entire (A), early (B) and late (C) spring periods based on the values presented in Fig. 4. In 1983, no impacts were calculated due to missing Daphnia data. 


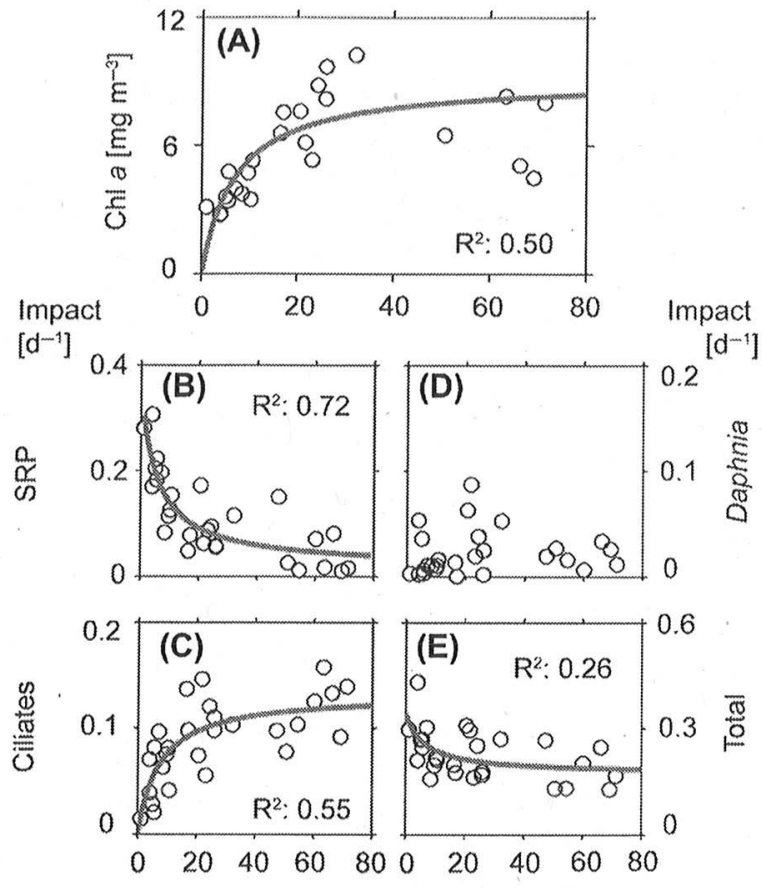

Figure 6. Top $20 \mathrm{~m}$ average chl $a$ concentration (A) and impact of phosphorus (B), ciliates (C), Daphnia (D) and their sum (E) during the entire spring versus average soluble reactive phosphate within the top $20 \mathrm{~m}$ during February-March $\left(\mathrm{SRP}_{\text {mix }}\right.$ ). Curves are scaled Monod-functions of the form $(y=c+a \times x)$ $(b+x))$. For herbivore impacts and $\operatorname{chl} a$ concentrations $c$ was assumed to be zero.

of a particular factor at a given moment, as the interactions between the non-manipulated factors (e.g. nutrients) and phytoplankton during the course of each 1-day manipulation experiment (e.g. herbivore removal) remain identical to those in the control run. Indirect effects developing at various time-scales, e.g. an increase in nutrient limitation during a herbivore removal experiment due to the lack of recycling (Sterner 1986) are not explicitly addressed in this study and their detailed investigation would require a fully dynamic model.

Our study highlights the scale dependency of the interactions between different factors regulating algal dynamics. On a daily time scale, the impacts of the different factors should not show strong interdependencies as for the quantification of the impact of one factor, the limitations brought about by the other factors were held constant. On the seasonal time scale, the impacts of phosphorus and herbivores increase from the start of the spring bloom towards the clear-water phase and thus are positively related (Fig. 3). Partially this positive relationship is caused by the seasonal build-up of herbivore, i.e. especially Daphnia biomass, which is an important phosphorous drain (Sommer et al. 2003). Hence, during the spring season not only phytoplankton growth but also population growth of herbivores decreases SRP concentrations thereby increasing phosphorus impacts. Finally, on the inter-annual time-scale impacts of ciliates decrease whereas impacts of phosphorous increase (Fig. 4). This negative correlation probably results from the tight coupling of ciliate dynamics with algal dynamics. In a recent meta-analysis, Gruner et al. (2008) did not detect a significant interaction between bottom-up and top-down regulation of primary producers. They suggested that the lack of interactions may have been due to the short duration of experimental studies, which did not allow multiple generations and feedbacks between regulating factors to develop. Our approach did allow consideration of long-term dynamics and feedbacks and indeed suggest interactions between top-down and bottom-up regulation. Furthermore, our data suggest that the nature of these interactions depended on the temporal scales considered, i.e. seasonal versus inter-annual time periods.

Quantification of impacts provides novel insights into the regulation of algal populations under seasonal and long-term environmental change, e.g. regarding the relative importance of different forcing factors for algal growth and biomass (chl a) development during oligotrophication. Average spring chl $a$ did not respond to a reduction of $S R P_{\text {mix }}$ concentrations during the first decade of our study period that was characterized by a $50 \%$ decline in $\mathrm{SRP}_{\text {mix }}$ from almost $80 \mu \mathrm{g} \mathrm{l}^{-1}$ in 1980 to less than $40 \mu \mathrm{g}^{-1}$ in the early 1990 s. Insensitivity of phytoplankton biomass to decreases in phosphorus levels in the early recovery phases of restoration efforts is a rather persistent pattern in lakes and coastal seas (Jeppesen et al. 2005, Duarte et al. 2009). This insensitivity has been attributed to excess availability of phosphorus resulting in the limitation of phytoplankton growth by e.g. herbivory, light availability or other nutrients such as nitrogen or silicate (Smith 1982, Tilzer et al. 1991). Phytoplankton growth during the spring period in Lake Constance was not limited by nitrogen or silicate (with the possible exception of pennate diatoms) even in the most eutrophic years (Gaedke and Schweizer 1993, Sommer et al. 1993) in contrast to the case in hyper-eutrophic lakes (Jeppesen et al. 2005, Huber et al. 2008). Nevertheless, our analysis illustrates that despite the strong decrease in $\mathrm{SRP}_{\text {mix }}$ in the 1980s phosphorus impacts indeed remained at low values, which explains that the change in trophic state during this time period did not significantly affect chl $a$ concentrations. However, the further decrease in $S_{R P} P_{\text {mix }}$ from the 1990s until today caused a substantial increase in the phosphorous impacts and was associated by a significant decline in phytoplankton biomass. Differential response of phytoplankton biomass to $S R P_{\text {mix }}$ is also supported by the better fit produced by a saturating function than a linear function (Fig. $6 \mathrm{~A}, \Delta \mathrm{AICc}>10$ ). The phosphorus impacts increased also non-linearly with oligotrophication and showed a hyperbolic relationship with $\mathrm{SRP}_{\text {mix }}$. The non-linear dependence of the phosphorous impacts on trophic state can be explained by the non-linear dependence of the specific production rate of algae on phosphorus concentration that was parameterized in our model by a Monod-function. At

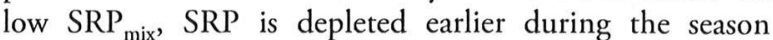
than at high SRP mix (Anneville et al. 2005). That is, during the eutrophic period, algal growth was limited by phosphorus only during a rather short part of the spring period (e.g. Fig. 3C) whereas in more oligotrophic years phosphorus limited algal growth starting from the 
beginning of the season (e.g. Fig. 3D). This analysis suggests that, irrespective of other processes (e.g. herbivory), the resource uptake dynamics alone can impose nonlinear relationships between producer and resource abundances (Fig. 6A), since the limitation exerted by the resource itself may become non-linearly related to its concentration during a specific seasonal period (Fig. 6B).

The strong increase of phosphorus impacts with $\mathrm{SRP}_{\text {mix }}$ resulted in a shift from top-down to bottom-up limitation of algae with oligotrophication (Fig. 5). This shift was further augmented by the simultaneous decline of herbivore, i.e. ciliate impacts (Fig. 4D-F). Because the increase in the phosphorus impacts was larger than the decrease in herbivore impacts, total impacts increased with decreasing $\mathrm{SRP}_{\text {mix }}$ similar to the phosphorus impacts (Fig. 6E). Considering that the range of phosphate concentrations in this study corresponds to a transition from $\mathrm{eu} / \mathrm{mesotrophic}$ to oligotrophic conditions, this finding is consistent with the 'mesotrophic maximum hypothesis' (Elser and Goldman 1991), predicting a reduced herbivore influence in oligotrophic conditions due to their low densities. However in our study the reduction of herbivore impacts was due to ciliates and not to daphnids as in Elser and Goldman (1991). Furthermore, the substantial non-linear increase in the impact of phosphorous with oligotrophication by itself would have been sufficient to cause a shift in the relative importance of nutrients versus herbivores for the regulation of phytoplankton.

The top-down impact exerted by a trophic level depends not only on the vertical structure of the food web, but also on the horizontal structuring, i.e. heterogeneity within a trophic level (Leibold et al. 1997). The inclusion of multiple herbivore taxa has been considered as one important future research goal in a recent meta-analysis (Gruner et al. 2008). Here, we show that in order to understand changes in top-down control on phytoplankton at different temporal scales it is indeed essential to consider at least two herbivore groups, i.e. mesozooplankton (daphnids) and microzooplankton (ciliates). On a seasonal scale, there is strong complementation in herbivory between ciliates and daphnids, as the two taxa contribute to herbivory at different extents during early and late spring periods. During most of the spring bloom the impact of ciliates is larger than the impact of Daphnia, demonstrating that ciliates play a major role in the control of phytoplankton in Lake Constance (Tirok and Gaedke 2006). However, our findings also point to rapid dynamics in the system. While the impact of ciliates is on average 5.4 times higher than that of Daphnia within the first week of late spring (between 21-14 days before CWP), Daphnia abundance increases about five-fold within two weeks and their average impacts become higher than the impact of ciliates during the last week of late spring (within last seven days before CWP). This rapid growth of Daphnia population contributes to the establishment of the wellknown clear-water phase (Lampert et al. 1986) and demonstrates the importance of considering impacts at a high temporal resolution. It has to be further noted that biomass specific impacts of herbivores increased throughout the season as a result of enhanced filtering rates by higher temperatures in late spring. Consequently, a two-fold higher average biomass of e.g. ciliates in the late spring period compared to early period, results in an approximately three-fold higher impact. An increase of top-down effects with higher temperatures has also been recently reported for mosquito predation on protozoa (Hoekman 2010).

On the long-term time scale, top-down impacts on spring phytoplankton declined with oligotrophication, only when ciliates are considered. While the impact, as well as the biomass of ciliates decreased with oligotrophication (Fig. 1D, 4D-F), that of Daphnia did not show a significant trend (Fig. 1C, 4G-I). This may point to differences between the regulation of Daphnia versus ciliates dynamics during the spring period. Daphnia dynamics during spring are strongly controlled by water temperatures rather than by food abundances (Schalau et al. 2008, Berger et al. 2010), and monthly average water temperatures have been shown to increase in Lake Constance during the last decades (Straile et al. 2003). However, allowing for the inter-annual variability of the start and end of the spring bloom periods removed any trends in the mean temperatures during this period $(\mathrm{p}=0.70)$. Consequently the spring Daphnia biomass and impacts did not show any trend for the 28 years covered in this study. In contrast, the decline of ciliate biomass and impacts with oligotrophication and the similar responses of ciliates and chl $a$ to $\mathrm{SRP}_{\text {mix }}$ (Fig. 6B-C) suggest that ciliate dynamics during spring are more closely coupled to food availability than the dynamics of daphnids, presumably because of the higher growth rates (Sherr and Sherr 2009) and over-wintering biomasses of ciliates compared to daphnids: in Lake Constance late winter (March) ciliate biomass was on average between 20-140 fold higher compared to Daphnia biomass depending on assumptions regarding the depth distribution of ciliates below $20 \mathrm{~m}$, i.e. no ciliates below $20 \mathrm{~m}$ versus homogenous ciliate distribution throughout the water column. The importance of ciliate impacts for understanding longterm changes in top-down regulation and the differences between the impacts of ciliates versus daphnids suggests that water quality models which are concerned with the effects of changes in trophic status on lake ecosystems (Mieleitner and Reichert 2006, Law et al. 2009) could profit from inclusion of an additional microzooplankton (e.g. ciliate) compartment.

\section{Conclusion and future prospects}

The approach presented here enabled quantification of phytoplankton limitation induced by various factors at a high temporal resolution and allowed comparison of topdown and bottom-up limitation on algal growth across seasonal to inter-decadal scales in an individual system undergoing oligotrophication. Our approach benefited from an exceptionally detailed data set and also from the focus on a comparatively low-complexity food-web. Application of the presented technique to other systems of a similar complexity is straightforward as long as sufficient data are availaible for model design and validation. It would be interesting to extend our approach to more complex systems or seasonal periods exhibiting a greater number of direct and indirect interactions. This would, 
however, also require a more detailed model that is capable to adequately account for the relevant mechanisms in a more complex food-web as well as the data and measurements for calibration and validation of the model. A promising first step for future progress thus may be the combination of our modelling approach with mesoscom experiments.

To conclude, our results show that consideration of multiple time scales and multiple herbivore taxa are important aspects for the understanding of the consequences of environmental change on bottom-up versus top-control in aquatic systems. Additionally, we show that the effect sizes of bottom-up and top-down control respond nonlinearly to changes in nutrient inflow thereby providing an additional explanation for the often observed resilience of phytoplankton dynamics to ecosystem restoration (Jeppesen et al. 2005, Duarte et al. 2009). As non-linear responses of processes are considered to be a requisite for abrupt shifts in ecosystem state, our results might contribute to a better understanding of such shifts reported for an increasing number of ecosystems (Scheffer et al. 2001).

Acknowledgements - The long-term data were mostly sampled within the DFG-funded Special Collaborative Programme 248 ('Cycling of matter in Lake Constance'). Meteorological data were kindly provided by the German National Meteorological Service (Deutscher Wetterdienst). We thank H. Rossknecht (Inst. für Seenforschung, Langenargen) for providing SRP concentrations. Funding was provided by the Deutsche Forschungsgemeinschaft (DFG) within the AQUASHIFT programme (SPP 1162, project 'MOPPS', PE 701/2-2).

\section{References}

Anderson, D. R. et al. 1998. Comparison of akaike information criterion and consistent akaike information criterion for model selection and statistical inference from capture-recapture studies. - J. Appl. Stat. 25: 263-282.

Anneville, O. et al. 2005. Phosphorus decrease and climate variability: mediators of synchrony in phytoplankton changes among european peri-alpine lakes. - Freshwater Biol. 50: 1731-1746.

Bakker, E. S. et al. 2006. Herbivore impact on grassland plant diversity depends on habitat productivity and herbivore size. - Ecol. Lett. 9: 780-788.

Bannister, T. T. 1974. Production equations in terms of chlorophyll concentration, quantum yield, and upper limit to production. - Limnol. Oceanogr. 19: 1-12.

Behrenfeld, M. J. et al. 2006. Climate-driven trends in contemporary ocean productivity. - Nature 444: 752-755.

Berger, S. A. et al. 2010. Water temperature and stratification depth independently shift cardinal events during plankton spring succession. - Global Change Biol. 16: 1954-1965.

Berlow, E. L. et al. 1999. Quantifying variation in the strengths of species interactions. - Ecology 80: 2206-2224.

Boyce, D. G. et al. 2010. Global phytoplankton decline over the past century. - Nature 466: 591-596.

Bruce, L. C. et al. 2006. A numerical simulation of the role of zooplankton in c, $\mathrm{n}$ and $\mathrm{p}$ cycling in Lake Kinneret, Israel. - Ecol. Modell. 193: 412-436.

Buitenhuis, E. T. et al. 2010. Biogeochemical fluxes through microzooplankton. - Global Biogeochem. Cycle 24.

Downing, J. A. et al. 1999. Meta-analysis of marine nutrientenrichment experiments: variation in the magnitude of nutrient limitation. - Ecology 80: 1157-1167.
Duarte, C. M. et al. 2009. Return to neverland: shifting baselines affect eutrophication restoration targets. - Estuaries Coasts 32: 29-36.

Edwards, A. M. and Yool, A. 2000. The role of higher predation in plankton population models. - J. Plankton Res. 22: $1085-1112$.

Elser, J. J. and Goldman, C. R. 1991. Zooplankton effects on phytoplankton in lakes of contrasting trophic status. - Limnol. Oceanogr. 36: 64-90.

Elser, J. J. et al. 2007. Global analysis of nitrogen and phosphorus limitation of primary producers in freshwater, marine and terrestrial ecosystems. - Ecol. Lett. 10: 1135-1142.

Gaedke, U. and Schweizer, A. 1993. The 1st decade of oligotrophication in Lake Constance. 1. The response of phytoplankton biomass and cell-size. - Oecologia 93: 268-275.

Gaedke, U. et al. 2002. Interplay between energy limitation and nutritional deficiency: empirical data and food web models. - Ecol. Monogr. 72: 251-270.

Geider, R. J. and Osborne, B. A. 1989. Respiration and microalgal growth - a review of the quantitative relationship between dark respiration and growth. - New Phytol. 112: 327-341.

Goudsmit, G. H. et al. 2002. Application of k-epsilon turbulence models to enclosed basins: the role of internal seiches. - J. Geophys. Res.-Oceans 107.

Gruner, D. S. et al. 2008. A cross-system synthesis of consumer and nutrient resource control on producer biomass. - Ecol. Lett. 11: 740-755.

Haese, C. 1996. Die vorhersage der produktivität des phytoplanktons im bodensee unter berücksichtigung der temperatur sowie der spektralen zuzammensetzung des unterwasserstrahlungsfeldes. - Univ. Konstanz.

Haese, C. U. et al. 1998. Phytoplankton response to reoligotrophication in large and deep lake constance: photosynthetic rates and chlorophyll concentrations. - Arch. Hydrobiol. Spec. Iss. Adv. Limnol. 53: 159-178.

Hairston, N. G. et al. 1960. Community structure, population control, and competition. - Am. Nat. 94: 421-425.

Hansen, P. J. et al. 1997. Zooplankton grazing and growth: scaling within the 2-2000-mu m body size range. - Limnol. Oceanogr. 42: 687-704.

Hoekman, D. 2010. Turning up the heat: temperature influences the relative importance of top-down and bottom-up effects. - Ecology 91: 2819-2825.

Huber, V. et al. 2008. Phytoplankton response to climate warming modified by trophic state. - Limnol. Oceanogr. 53: 1-13.

Hughes, T. P. 1994. Catastrophes, phase-shifts, and large-scale degradation of a caribbean coral-reef. - Science 265: $1547-1551$.

Jeppesen, E. et al. 2005. Lake responses to reduced nutrient loading - an analysis of contemporary long-term data from 35 case studies. - Freshwater Biol. 50: 1747-1771.

Lampert, W. et al. 1986. Phytoplankton control by grazing zooplankton - a study on the spring clear-water phase. - Limnol. Oceanogr. 31: 478-490.

Law, T. et al. 2009. Structural changes in lake functioning induced from nutrient loading and climate variability. - Ecol. Modell. 220: 979-997.

Leibold, M. A. 1989. Resource edibility and the effects of predators and productivity on the outcome of trophic interactions. - Am. Nat. 134: 922-949.

Leibold, M. et al. 1997. Species turnover and the regulation of trophic structure. - Annu. Rev. Ecol. Syst. 28: 467-494.

McQueen, D. J. et al. 1989. Bottom-up and top-down impacts on fresh-water pelagic community structure. - Ecol. Monogr. 59: 289-309.

Menge, B. A. 2000. Top-down and bottom-up community regulation in marine rocky intertidal habitats. - J. Exp. Mar. Biol. Ecol. 250: 257-289. 
Meserve, P. L. et al. 2003. Thirteen years of shifting top-down and bottom-up control. - Bioscience 53: 633-646.

Miehe, S. et al. 2010. Long-term degradation of sahelian rangeland detected by 27 years of field study in Senegal. - J. Appl. Ecol. 47: 692-700.

Mieleitner, J. and Reichert, P. 2006. Analysis of the transferability of a biogeochemical lake model to lakes of different trophic state. - Ecol. Modell. 194: 49-61.

Oksanen, L. et al. 1981. Exploitation ecosystems in gradients of primary productivity. - Am. Nat. 118: 240-261.

Osenberg, C. W. and Mittelbach, G. G. 1996. The relative importance of resource limitation and predator limitation in food chains. - In: Polis, G. A. and Winemiller, K. O. (eds), Food webs: integration of patterns and dynamics. Chapman and Hall, pp. 134-148.

Peeters, F. et al. 2002. Modeling 50 years of historical temperature profiles in a large central european lake. - Limnol. Oceanogr. 47: 186-197.

Peeters, F. et al. 2007a. Earlier onset of the spring phytoplankton bloom in lakes of the temperate zone in a warmer climate. - Global Change Biol. 13: 1898-1909.

Peeters, F. et al. 2007b. Turbulent mixing and phytoplankton spring bloom development in a deep lake. - Limnol. Oceanogr. 52: 286-298.

Persson, L. 1999. Trophic cascades: abiding heterogeneity and the trophic level concept at the end of the road. - Oikos 85: 385-397.

Santer, B. and Van den bosch, F. 1994. Herbivorous nutrition of Cyclops vicinus - the effect of a pure algal diet on feeding, development, reproduction and life-cycle. - J. Plankton Res. 16: 171-195.

Schalau, K. et al. 2008. Temperature is the key factor explaining interannual variability of daphnia development in spring: a modelling study. - Oecologia 157: 531-543.

Scheffer, M. et al. 2001. Catastrophic shifts in ecosystems. - Nature 413: 591-596.

Sherr, E. B. and Sherr, B. F. 2009. Capacity of herbivorous protists to control initiation and development of mass phytoplankton blooms. - Aquat. Microbiol. Ecol. 57: 253-262.

Smith, V. H. 1982. The nitrogen and phosphorus dependence of algal biomass in lakes - an empirical and theoretical-analysis. - Limnol. Oceanogr. 27: 1101-1112.

Smith, V. H. and Schindler, D. W. 2009. Eutrophication science: where do we go from here? - Trends Ecol. Evol. 24: 201-207.

Sommer, U. 1984. Sedimentation of principal phytoplankton species in lake constance. - J. Plankton Res. 6: 1-14.

Sommer, U. et al. 1986. The peg-model of seasonal succession of planktonic events in fresh waters. - Arch. Hydrobiol. 106: 433-471.
Sommer, U. et al. 1993. The 1st decade of oligotrophication of Lake Constance. 2. The response of phytoplankton taxonomic composition. - Oecologia 93: 276-284.

Sommer, F. et al. 2003. Daphnia population growth but not moulting is a substantial phosphorus drain for phytoplankton. - Freshwater Biol. 48: 67-74.

Steele, J. H. and Henderson, E. W. 1981. A simple plankton model. - Am. Nat. 117: 676-691.

Sterner, R. W. 1986. Herbivores direct and indirect effects on algal populations. - Science 231: 605-607.

Stich, H. B. and Brinker, A. 2010. Oligotrophication outweighs effects of global warming in a large, deep, stratified lake ecosystem. - Global Change Biol. 16: 877-888.

Straile, D. 1997. Gross growth efficiencies of protozoan and metazoan zooplankton and their dependence on food concentration, predator-prey weight ratio and taxonomic group. - Limnol. Oceanogr. 42: 1375-1385.

Straile, D. 2000. Meteorological forcing of plankton dynamics in a large and deep continental european lake. - Oecologia 122: $44-50$.

Straile, D. et al. 2003. Complex effects of winter warming on the physicochemical characteristics of a deep lake. - Limnol Oceanogr. 48: 1432-1438.

Tilzer, M. M. 1988. Secchi disk - chlorophyll relationships in a lake with highly variable phytoplankton biomass. - Hydrobiologia 162: 163-171.

Tilzer, M. M. et al. 1991. Interannual variability of phytoplankton productivity and related parameters in lake constance - no response to decreased phosphorus loading. - J. Plankton Res. 13: 755-777.

Tirok, K. and Gaedke, U. 2006. Spring weather determines the relative importance of ciliates, rotifers and crustaceans for the initiation of the clear-water phase in a large, deep lake. - J. Plankton Res. 28: 361-373.

Von Liebig, J. 1840. Die chemie in ihrer anwendung auf agrikultur and physiologie. - Vieweg.

Weisse, T. 2006. Freshwater ciliates as ecophysiological model organisms - lessons from daphnia, major achievements and future perspectives. - Arch. Hydrobiol. 167: 371-402.

Weisse, T. and Mueller, H. 1998. Planktonic protozoa and the microbial food web in lake constance. - Arch. Hydrobiol. Spec. Iss. Adv. Limnol. 53: 223-254.

Weisse, T. et al. 1990. Response of the microbial loop to the phytoplankton spring bloom in a large prealpine lake. - Limnol. Oceanogr. 35: 781-794.

Weisse, T. et al. 2001. Niche separation in common prostome freshwater ciliates: the effect of food and temperature. - Aquat. Microb. Ecol. 26: 167-179.

Winder, M. and Schindler, D. E. 2004. Climate change uncouples trophic interactions in an aquatic ecosystem. - Ecology 85: 2100-2106. 